\title{
Case report: lactic acidosis and rhabdomyolysis during telbivudine and tenofovir treatment for chronic hepatitis B
}

\author{
Yue Ying ${ }^{\dagger}$, Yue-Kai Hü ${ }^{\dagger}$ Jia-Lin Jin, Ji-Ming Zhang, Wen-Hong Zhang and Yu-Xian Huang ${ }^{*}$
}

\begin{abstract}
Background: Current treatment options for chronic hepatitis B (CHB) are pegylated interferon alpha and nucleoside analogues (NAs). NAs have relatively fewer side effects than interferon alpha, and generally well tolerated. Previously 12.9\% of patients on telbivudine treatment were reported to develop severe elevation of serum creatine phosphokinase (CPK) levels, but related clinical disease, like lactic acidosis (LA) and rhabdomyolysis (RM) were rare. The pathophysiology may be mitochondrial toxicity, for the NAs inhibit not only hepatitis B virus (HBV) polymerase, but also the host mitochondrial DNA polymerase $\gamma$. As mitochondria are the main sites of oxidative phosphorylation, there will be an increase of pyruvate reduction to lactic acid and insufficient adenosine triphosphate. The accumulation of lactic acid causes $L A$, while lack of energy leads to cell dysfunction and mitochondria-associated disease, including RM. All five NAs, except tenofovir, have been reported causing LA and RM. Here we report the first case of CHB patients developing fatal LA and RM during telbivudine and tenofovir treatment.

Case presentation: The patient is a 51-year-old man who was hospitalized in November 2015. He had taken telbivudine regularly because of CHB. Later, tenofovir was added to antiviral treatment because of HBV resistance. Then he had myalgia, chest tightness and anorexia. The blood lactate was $12.7 \mathrm{mmol} / \mathrm{L}$. The arterial blood gas analysis showed pH 7 . 25, base excess $21.1 \mathrm{mmol} / \mathrm{L}$. CPK was $991 \mathrm{U} / \mathrm{L}$, myoglobin was $1745 \mathrm{ng} / \mathrm{ml}$ and creatine was 83 umol/L. Abdomen magnetic resonance revealed cirrhosis. Muscle biopsy revealed myogenic lesion with abnormality of mitochondria and fat metabolism. The patient was diagnosed with Hepatitis B envelope Antigen positive CHB, cirrhosis, LA and RM characterized by myalgia and elevated myoglobin. He was given tenofovir alone as antiviral treatment instead. After hemodialysis and 4 weeks' treatment of corticosteroids, his symptoms recovered, and blood lactate gradually returned to a normal range.

Conclusions: This case shows that tenofovir may trigger muscle damage and fatal RM in combination with telbivudine treatment in CHB patients. Thus, patients receiving tenofovir and telbivudine should be closely monitored for muscular abnormalities, blood lactate level and other mitochondrial toxicity associated side effects.
\end{abstract}

Keywords: Lactic acidosis, Rhabdomyolysis, Mitochondrial toxicity, Myopathy, Telbivudine, Tenofovir

\section{Background}

Current treatment options for chronic hepatitis B (CHB) are pegylated interferon alpha and nucleoside analogues (NAs) including telbivudine. These agents suppress hepatitis B virus (HBV) DNA effectively so that significantly decreasing the risk of hepatocellular carcinoma. NAs have relatively fewer side effects than interferon

\footnotetext{
* Correspondence: yxhuang@fudan.edu.cn

${ }^{\dagger}$ Equal contributors

Department of Infectious Diseases, Huashan Hospital Affiliated to Fudan

University, 12, Middle Wulumuqi Road, Shanghai 200040, China
}

alpha, and generally well tolerated [1]. Infrequent but serious adverse events have been reported in clinical trials and post-marketing surveillance in individual cases. Previously $12.9 \%$ of patients on telbivudine treatment developing severe elevation of serum creatine phosphokinase (CPK) levels [2], but lactic acidosis (LA) and rhabdomyolysis (RM) were rare. These two diseases may due to the same pathophysiology: mitochondrial toxicity. The NAs inhibit HBV polymerase and also have a low level of activity against the host mitochondrial DNA polymerase $\gamma$, leading to impaired replication with 
mitochondrial loss or dysfunction. As mitochondria are the main sites of oxidative phosphorylation, there will be an increase of pyruvate reduction to lactic acid and insufficient ATP. The accumulation of lactic acid causes LA, while lack of energy leads to cell dysfunction and mitochondria-associated disease, including RM. Here we report the first case of $\mathrm{CHB}$ patients developing fatal LA and RM during telbivudine and tenofovir treatment.

\section{Case presentation}

In November 2015, a 51-year-old man was hospitalized because of myalgia for more than 1 month. He had a history of Hepatitis B envelope Antigen (HBeAg) positive hepatitis B for 13 years without being treated with antiviral drug. Two years before admission, he was diagnosed with hepatitis $\mathrm{B}$ and cirrhosis by local hospital, and HBV DNA was $6.5^{*} 10^{3}$ copies $/ \mathrm{ml}$. Then he began to take telbivudine regularly and HBV DNA became undetected after some time. However, two months before admission, HBV DNA again reached $7^{*} 10^{3}$ copies $/ \mathrm{ml}$. Considering HBV resistance to telbivudine, the antiviral treatment converted to the combination of telbivudine and tenofovir. After taking combination treatment, he began to feel muscle pain, especially in both lower limbs after walking. He also had hypoesthesia in distal limbs. There were no other concurrent symptoms, such as fever, headache, abdominal pain and altered level of consciousness. The symptoms became increasingly heavier. After 1 month of combination treatment, telbivudine and tenofovir were discontinued, and he began to take adefovir instead. However, his symptoms didn't relieve. Ten days before admission, laboratory testing revealed an elevated alanine aminotransferase (ALT, $66 \mathrm{U} / \mathrm{L}$ ), aspartate transaminase (AST, $129 \mathrm{U} / \mathrm{L}$ ), lactate dehydrogenase (LDH, 474 U/L) and CPK (1050 U/L). Total bilirubin and indirect bilirubin level were normal. To rule out liver cancer, abdomen magnetic resonance (MRI) was done, which revealed cirrhosis and gallstone. The patient received liver-protecting treatment. Two days before admission, he had chest tightness and short of breath. The blood lactate level was $12.7 \mathrm{mmol} / \mathrm{L}$. The arterial blood gas analysis showed $\mathrm{pH} 7.25$, base excess -21 . $1 \mathrm{mmol} / \mathrm{L}$. The patient received sodium bicarbonate $\left(\mathrm{NaCO}_{3}\right)$ for the treatment of acidosis and eventually transferred to our hospital diagnosed with LA and RM. On the day of admission, he began to develop chest tightness and palpitation. The blood routine test showed normal white blood cell count and percentage of neutrophils. His urine color was black and urine output was about $200 \mathrm{ml}$ per day. ALT was $77 \mathrm{U} / \mathrm{L}$, total bilirubin was $25.2 \mu \mathrm{mol} / \mathrm{L}, \mathrm{CPK}$ was $991 \mathrm{U} / \mathrm{L}, \mathrm{LDH}$ was $509 \mathrm{U} / \mathrm{L}$, creatine was $83 \mu \mathrm{mol} / \mathrm{L}$, myoglobin was $1745 \mathrm{ng} / \mathrm{ml}$ and lactic acid was $20 \mathrm{mmol} / \mathrm{L}$. The electrolytes test was normal, while uric acid was $1.019 \mathrm{mmol} / \mathrm{L}$. HBV markers showed Hepatitis B surface Antigen (HBsAg), HBeAg and Hepatitis B core Antibody (HBcAb) were positive, while HBV DNA was undetected. Physical examination on admission revealed swelling and tenderness of all his extremities, muscle dumbness and weakness in both lower limbs, which quantitative value was 3 grade without redness and warm skin. Besides chronic hepatitis, the patient denied a past history of significant comorbidities, including diabetes and chronic kidney disease. $\mathrm{He}$ had no previous trauma and also denied any other drug, Chinese herb and nutritional supplementary use except antiviral drug for $\mathrm{CHB}$.

Low extremity MRI showed mild atrophy in both lower extremities and increased signal intensity (Fig. 1), consistent with the manifestation of myopathy. Electromyography revealed multiple peripheral neuropathy with predominant motor and sensory axonal injury. Muscle biopsy on left biceps revealed myogenic lesion with abnormality of mitochondria and fat metabolism (Fig. 2). Muscle fibers are of variable size and irregular shape, with scattered atrophy and degeneration. In atrophic fibers, Modified Gomori trichrome (MGT) stain showed red granular changes, with increased succinic dehydrogenase (SDH) activity and negative cytochrome oxidase (COX) activity.

As the patient had myalgia, oliguria and black urine, combining with serum myoglobulin $>500 \mu \mathrm{g} / \mathrm{L}$, severe metabolic acidosis and his past medical history, he was diagnosed with RM, LA and HBeAg negative CHB. Without the history of injury, other concurrent drug intake and infection, we concluded that RM was caused by telbivudine and tenofovir.

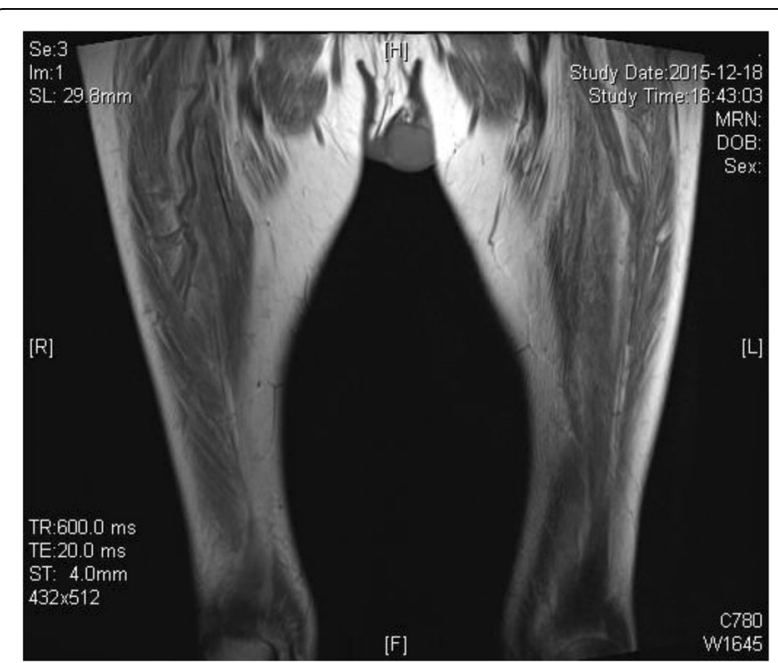

Fig. 1 The low extremity MRI. Mild atrophy of both thigh muscle with uniformly increased signal intensity, which is accordant with the features of myopathy 


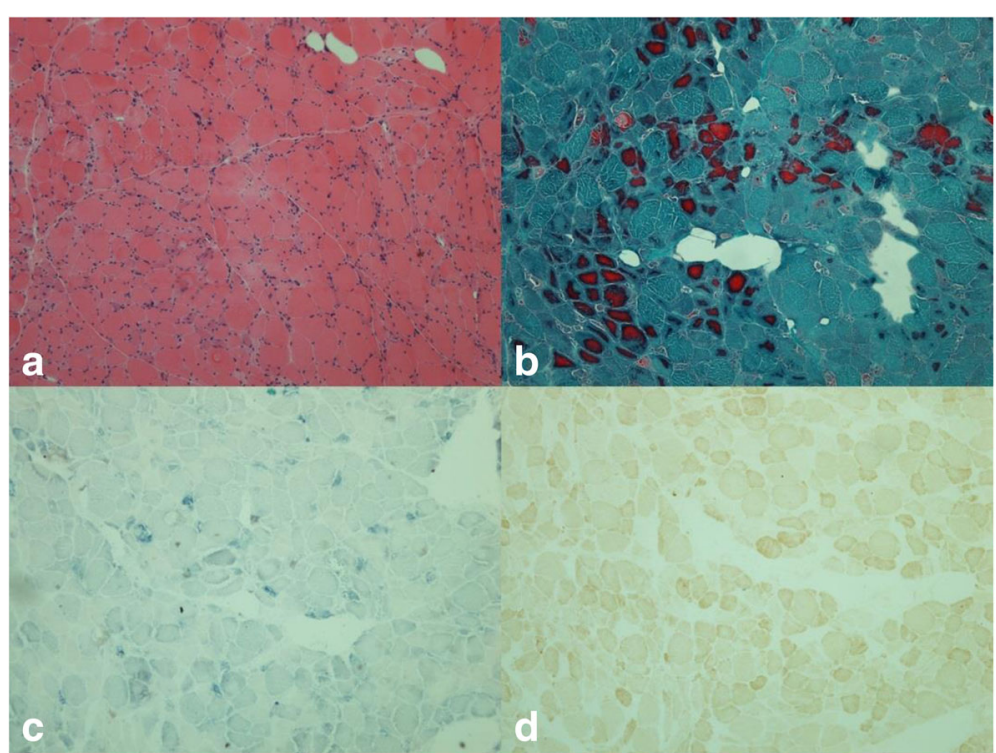

Fig. 2 Microscopic findings of muscle biopsy specimen showed mitochondrial toxicity. a Muscle fibers are of variable size and irregular shape, and there are many atrophic and degenerating muscle fibers. (HE, magnification $\times 200)$; b A lot of red granular changes in atrophic fibers. (modified Gomori trichrome stain, magnification × 200); c Increased enzyme activities in many atrophic fibers. (succinic dehydrogenase, magnification × 200); d Many muscle fibers are deficient for enzyme activities. (cytochrome oxidase stain, magnification $\times 200$ )

After admission, the antiviral treatment converted to entecavir because of its lower reporting portion of muscle-related adverse drug reaction. The patient was given hemodialysis twice. He was also given hydration, alkalization and supplementation treatment. After one week, the blood lactate, myoglobin and CPK dropped rapidly, but the blood lactate level fluctuated between 3 and $5 \mathrm{mmol} / \mathrm{L}$ (Fig. 3). His arterial blood gas analysis returned to normal, showing $\mathrm{pH}$ between 7.40 and 7.45. Then he received tenofovir disoproxil instead of entecavir and methylprednisolone for $40 \mathrm{mg}$ each day. In the following four weeks, blood lactate reduced to normal range and didn't rebound. Five months later, the patient could walk naturally. His dumbness in distal limbs relieved but still existed. (Table 1) During the whole period from 2015.9 (before taking tenofovir) to 2016.6, the patient's renal function was normal and GFR levels were estimated between 106.1 to $120.2 / \mathrm{ml} / \mathrm{min} / 1.73 \mathrm{~m}^{2}$.

\section{Discussion and Conclusions}

In basic terms, lactic acid is the product of anaerobic metabolism. The normal blood lactate concentration is 0.5$1 \mathrm{mmol} / \mathrm{L}$. LA is defined as a constant increase in blood lactate levels (usually $>5 \mathrm{mmol} / \mathrm{L}$ ) in association with metabolic acidosis (usually present as $\mathrm{pH}<7.3$ and serum bicarbonate $<10 \mathrm{mmol} / \mathrm{L}$ ) [1]. The LA syndrome presents as steatosis, abnormal mitochondrial appearance and function, pancreatitis, neuropathy, and myopathy. The onset may be abrupt or insidious, which generally begins with nausea, vomiting, and abdominal pain. It will progress to tachypnea, shortness of breath, and hypoxia. Patients with severe LA may subsequently develop renal failure, liver failure, coagulopathy, seizures, arrhythmias, and even death. The patient reported here was a severe LA case with a constant higher lactate level (more than $12 \mathrm{mmol} / \mathrm{L}$ ) and $\mathrm{pH}$ value (about 7.2).

On the other hand, RM is a syndrome characterized by damage of striated muscle cells, which release a large amount of intracellular substance, including myoglobin, potassium ion, CPK, etc. The prognosis of RM is poor, and fatality rate reaches $3 \% \sim 27 \%$. Early symptoms are mild and non-specific, like malaise, muscular weakness and tenderness. The most important clinical manifestations are myoglobinuria and higher specific gravity of urine (>1.025). The color of urine can change from pale red to deep red, even black. CPK rises rapidly, up to 10,000-20,000 U/L. Blood gas analysis can reveal hypoxemia and metabolic acidosis. The diagnosis criteria are as follows: 1 . Serum CPK significantly rise; 2 . Blood and urine myoglobulin positive, with myalgia and muscle swollen; 3. Hyperkalemia, hyperphosphatemia, hyperuricemia and hypocalcemia. About 20\% 33\% RM patients will develop acute renal failure. RM is usually caused by trauma or non-trauma factors (like drugs, toxics, ischemia, and infection). Drugs that can induce RM contain statins, theophylline, anti-H1, benzodiazepines, amphotericin $\mathrm{B}$ and antidepressants [3].

In this case, the patient developed fatal syndrome LA and RM, after taking telbivudine and tenofovir as antiviral treatment. Without evidence of other causes like infection 


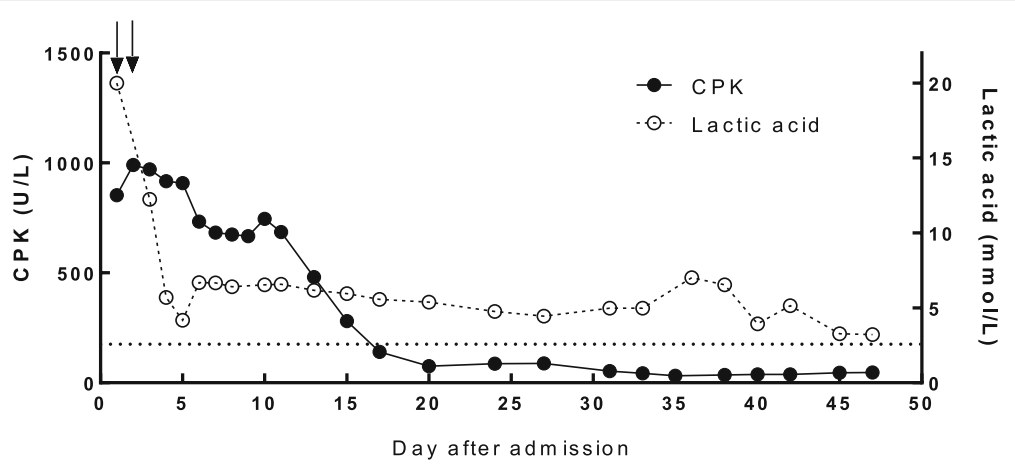

Fig. 3 Progression of serum creatine kinase (CPK) and lactic acid level. The dotted line indicates normal level. Each arrow shows one hemodialysis. The CPK and lactic acid level dropped quickly after hemodialysis

or trauma, telbivudine and tenofovir may be the cause of their complications.

Telbivudine is a potent nucleoside analogue for treatment of chronic hepatitis B, while it was often associated with muscle-related adverse events. During the large, multinational registration trials, telbivudine was reported a significantly higher side effect of grade 3 to 4 CPK elevations (defined as 7 times upper limit of normal) in two years compared to lamivudine [4]. In the phase III GLOBE trial, despite $12.9 \%$ of patients on telbivudine developing severe elevation of serum CPK levels, clinical myopathy was reported only in two (0.3\%) patients [2]. Another study monitored CPK levels of 200 patients who were treated with telbivudine for chronic hepatitis $\mathrm{B}$, the 3-year cumulative incidence of CPK elevations and myopathy was $84.3 \%$ and $5 \%$, respectively. Male, younger age and HBeAg negativity were independent predictors of CPK elevations. CPK elevations usually occurred 21 months after starting treatment. However, no risk factors of myopathy were identified [5]. As a result, although an elevated CPK may be an early indicator of muscle injury, this may be nonspecific and can often be elevated due to strenuous or prolonged exercise.

Table 1 The timeline of the patient's medical history and interventions

\begin{tabular}{|c|c|c|c|}
\hline Dates & Summaries & Diagnostic Testing & Interventions \\
\hline 2002 & Found HBV infection & HBsAg, HBeAg, HBcAb positive & No antiviral treatment \\
\hline 2013 & Diagnosed with cirrhosis & HBV DNA: $6.5^{*} 10^{3}$ copies $/ \mathrm{ml}$ & Telbivudine \\
\hline 2013-2015.9 & & HBV DNA undetected & Telbivudine \\
\hline 2015.9 & & HBV DNA: $7^{*} 10^{3}$ copies $/ \mathrm{ml}$ & $\begin{array}{l}\text { Telbivudine and } \\
\text { Tenofovir }\end{array}$ \\
\hline 2015.9-2015.10 & $\begin{array}{l}\text { Myalgia and hypoesthesia } \\
\text { in both lower limbs }\end{array}$ & & $\begin{array}{l}\text { Telbivudine and } \\
\text { Tenofovir }\end{array}$ \\
\hline 2015.10 & $\begin{array}{l}\text { Myalgia and hypoesthesia } \\
\text { not relieved }\end{array}$ & & Adefovir \\
\hline 2015.11.17 & $\begin{array}{l}\text { Myalgia and hypoesthesia } \\
\text { not relieved }\end{array}$ & ALT 66 U/L, LDH 474 U/L, CPK 1050 U/L & Adefovir; liver-protecting treatment \\
\hline 2015.11 .25 & $\begin{array}{l}\text { Myalgia and hypoesthesia } \\
\text { not relieved; Chest tightness } \\
\text { and short of breath occurred }\end{array}$ & $\begin{array}{l}\text { Blood lactate } 12.7 \mathrm{mmol} / \mathrm{L}, \\
\text { arterial blood gas: } \mathrm{pH} 7.25, \\
\text { base excess }-21.1 \mathrm{mmol} / \mathrm{L}\end{array}$ & Adefovir; liver-protecting treatment \\
\hline $\begin{array}{l}\text { 2015.11.27 } \\
\text { (Admission) }\end{array}$ & $\begin{array}{l}\text { Myalgia, hypoesthesia, chest tightness, } \\
\text { short of breath, palpitation; Swelling } \\
\text { and tenderness of all extremities, } \\
\text { muscle dumbness and grade } 3 \\
\text { strength in both lower limbs }\end{array}$ & $\begin{array}{l}\text { ALT: } 77 \mathrm{U} / \mathrm{L}, \text { TBil: } 25.2 \mu \mathrm{mol} / \mathrm{L} \text {, } \\
\text { CPK: } 991 \mathrm{U} / \mathrm{L}, \mathrm{LDH}: 509 \mathrm{U} / \mathrm{L}, \\
\text { creatine: } 83 \mu \mathrm{mol} / \mathrm{L}, \\
\text { myoglobin: } 1745 \mathrm{ng} / \mathrm{ml}, \\
\text { blood lactate: } 20 \mathrm{mmol} / \mathrm{L}, \\
\text { HBV DNA undetected }\end{array}$ & Entecavir; hemodialysis; hydration; alkalization \\
\hline 2015.12.4 & Nearly all symptoms relieved gradually & CPK 683 U/L, blood lactate $6.67 \mathrm{mmol} / \mathrm{L}$ & Tenofovir, Methylprednisolone $40 \mathrm{mg}$ qd \\
\hline 2016.1 .13 & Swelling of lower limbs disappeared & CPK $47 \mathrm{U} / \mathrm{L}$, blood lactate $3.21 \mathrm{mmol} / \mathrm{L}$ & Tenofovir \\
\hline 2016.6 & $\begin{array}{l}\text { Walk naturally; Dumbness in distal } \\
\text { limbs relieved but still existed }\end{array}$ & HBV undetected & Tenofovir \\
\hline
\end{tabular}

HBV Hepatitis B virus, $H B s A g$ Hepatitis B surface Antigen, $H B e A g$ Hepatitis B envelope Antigen, $H B c A b$ Hepatitis B core Antibody, ALT Alanine aminotransferase, $L D H$ Lactate dehydrogenase, CPK Creatine phosphokinase, TBil Total Bilirubin 
Telbivudine-associated myopathy generally occurred after taking drugs for more than one year, more common in male patients, presenting as myalgia, muscle weakness and elevated CPK [6]. Without any management, it possibly develops to RM. Yi et al. [7] has collected a total of 22 RM cases associated with telbivudine. All the cases were male patients with an average age of $(34.5 \pm 11.2)$ years. Half of the patients occurred RM within 6 to 10 months. Clinical manifestations were mostly nausea, vomiting, palpitations, weakness and edema of the lower extremities. After discontinuing telbivudine and getting symptomatic treatments, 4 deaths were still reported.

Long-term telbivudine treatment also make some patients develop resistance. This patient we reported also had a history of telbivudine resistance. At first, we converted antiviral therapy to entecavir because its lower reporting portion of muscle-related adverse drug reaction. As entecavir and telbivudine shared cross-resistance in some HBV variants, it was recommended that tenofovir should be the rescue strategy when telbivudine resistance occurred according to EASL guidelines in 2017 [8]. On the other side, tenofovir disoproxil fumarate was recommended as first-line monotherapy against hepatitis B with a high barrier to resistance [8]. So far, tenofovir was only reported a side effect of rhabdomyolysis during antiretroviral treatment in HIV patients, which combined with other concurrent antiretroviral drugs $[9,10]$. In a clinical trial studying the safety of tenofovir monotherapy for 5 years [11], the researchers reported no fatal adverse reaction like LA or RM. So, we thought tenofovir monotherapy was safe. When the patients' condition was steady, we used tenofovir under close monitoring. In another two large trials that have investigated the safety of telbivudine and tenofovir combination therapy in $\mathrm{CHB}$ patients during at most 1 year's follow-up, there were no muscle-related severe adverse events reported, like myopathy, LA and RM [12, 13]. For this patient we reported, he took telbivudine for two years and suffered myalgia immediately after addition of tenofovir, so we conjure that tenofovir sometimes may still have a synergistic effect on the development of myopathy after much longer medication time, especially in patients with cirrhosis.

The pathophysiology of NAs associated LA and RM is likely to be the malfunction of mitochondria [14, 15]. For according to muscle biopsy, the mitochondrial damage is identified in both patients. All five of the approved oral antiviral agents for HBV treatment can inhibit the polymerase activity of HBV. At the same time, they also have a low level of activity against the human mitochondrial DNA polymerase gamma and can lead to impaired mitochondrial replication with mitochondrial loss or dysfunction. Mitochondria are the main sites for oxidative phosphorylation and producing adenosine transferase (ATP). There are approximately 300-400 mitochondria in each cell. When mitochondria function is impaired or the number of mitochondria is decreased, there will be an impact on the aerobic metabolism and production of ATP. Lack of aerobic metabolism resulted in the increase of pyruvate reduction to lactic acid. Then the accumulation of lactic acid causes LA. On the other side, the insufficient ATP means lack of energy for cell activities, leading to dysfunction of cells and mitochondria-associated disease. Mitochondria are mainly distributed over organs and tissues which are metabolically active. Thus, the clinical manifestations of mitochondria toxicity vary based on the affected tissues, which may include myopathy, neuropathy, hepatic steatosis, pancreatitis, and nephrotoxicity. All NAs have a "black box" warning regarding potential mitochondrial toxicity in their product labeling.

For all five NAs approved of treatment for hepatitis B, the strength of inhibition of mtDNA polymerase gamma in an in vitro test system is substantially lower than antiretroviral agents like zalcitabine [1]. In particular, entecavir has demonstrated little evidence of mitochondrial toxicity compared to the other available agents at concentrations exceeding 100 times the maximum concentration seen in humans [16]. The impact of drug combinations in causing additive or synergistic mitochondrial toxicity in vitro has not been well studied.

Except drug withdrawal immediately, other management options for this kind of serious adverse reaction may include renal replacement therapy, bicarbonate alkalization and supplementation with L-acetylcarnitine, thiamine, as well as Coenzyme Q 10 to improve mitochondrial function. Most of the LA cases can resolve rapidly after discontinuation of the causative drug. For telbivudine associated myopathy, CPK decrease after 2-4 weeks as the symptoms are improved.

This case shows that tenofovir may trigger rhabdomyolysis in combination with telbivudine treatment in chronic hepatitis B patients. Thus, patients receiving tenofovir and telbivudine should be closely monitored for muscular abnormalities, blood lactate level and other mitochondrial toxicity associated side effects.

\footnotetext{
Abbreviations

ALT: Alanine aminotransferase; AST: Aspartate transaminase; ATP: Adenosine transferase; CHB: Chronic hepatitis B; COX: Cytochrome oxidase; CPK: Creatine phosphokinase; HBCAb: Hepatitis B core Antibody; HBeAg: Hepatitis B envelope Antigen; HBsAg: Hepatitis B surface Antigen; HBV: Hepatitis B virus; LA: Lactic acidosis; LDH: Lactate dehydrogenase; MGT: Modified Gomori trichrome; MRI: Magnetic resonance; NAs: Nucleoside analogues; RM: Rhabdomyolysis; SDH: Succinic dehydrogenase; TBil: Total Bilirubin

Acknowledgments

Not applicable.

Funding

Project 81670560 supported by National Natural Science Foundation of China. The funders had no role in study design, data collection and analysis, decision to publish, or preparation of the manuscript.
} 


\section{Availability of data and materials}

Data sharing is not applicable to this article as no datasets were generated or analyzed during the current study.

\section{Authors' contributions}

YY wrote the manuscript; HYK diagnosed and treated the patient, also designed Fig. 2; J JL helped to draft the manuscript and revised written English; ZJM and ZWH helped diagnose and manage the patients and draft the manuscript; HYX helped to draft the manuscript and revised it critically for important intellectual content; all authors have read and approved the final manuscript, and ensured that this is the case.

\section{Ethics approval and consent to participate}

Written informed consent to participate in the study from the patient was obtained.

\section{Consent for publication}

Written informed consent for publication from the patient was obtained.

\section{Competing interests}

The authors declare that they have no competing interests.

\section{Publisher's Note}

Springer Nature remains neutral with regard to jurisdictional claims in published maps and institutional affiliations.

Received: 16 August 2017 Accepted: 27 March 2018

Published online: 06 April 2018

\section{References}

1. Fontana RJ. Side effects of long-term oral antiviral therapy for hepatitis B. Hepatology. 2009;49:S185-95.

2. Liaw YF, Gane E, Leung N, Zeuzem S, Wang Y, Lai CL, Heathcote EJ, Manns M, Bzowej N, Niu J, Han SH, Hwang SG, Cakaloglu Y, Tong MJ, Papatheodoridis G, Chen Y, Brown NA, Albanis E, Galil K, Naoumov NV, GLOBE Study Group. 2-Year GLOBE trial results: telbivudine is superior to lamivudine in patients with chronic hepatitis B. Gastroenterology. 2009;136(2):486-95.

3. Caroleo B, Galasso O, Staltari O, Girofrè C, De Sarro G, Guadagnino V, Gallelli L. Muscular damage during telbivudine treatment in a chronic hepatitis $B$ patient. Muscles, Ligaments and Tendons Journal. 2011;1(2):57-60.

4. Chan HL, Chen YC, Gane EJ, Sarin SK, Suh DJ, Piratvisuth T, Prabhakar B, Hwang SG, Choudhuri G, Safadi R. Randomized clinical trial: efficacy and safety of telbivudine and lamivudine in treatment-naïve patients with HBVrelated decompensated cirrhosis. J Viral Hepat. 2012;19:732-43.

5. Zou XJ, Jiang XQ, Tian DY. Clinical features and risk factors of creatine kinase elevations and myopathy associated with telbivudine. J Viral Hepat. 2011;18(12):892-6.

6. Ambang T, Tan JS, Ong S, Wong KT, Goh KJ. Clinicopathological Features of Telbivudine-Associated Myopathy. PLoS One. 2016;11(9):e0162760.

7. Yi ZM, Tang SD, Fang L, Zhai SD, Jiao LG. Evaluation on telbivudineassociated rhabdomyolysis. J Clin Pharm Sci. 2016;25(1):66-72.

8. Lampertico P, Agarwal K, Berg T, Buti M, Janssen HLA, Papatheodoridis G, Zoulim F, Tacke F. EASL 2017 Clinical Practice Guidelines on the management of hepatitis B virus infection. J Hepatol. 2017;67(2):370-98.

9. Suttels V, Florence E, Leys J, Vekemans M, Van den Ende J, Vlieghe E, Kenyon C. A 68-year old male presenting with rhabdomyolysis-associated acute kidney injury following concomitant use of elvitegravir/cobicistat/ emtricitabine/tenofovir disoproxil fumarate and pravastatin/fenofibrate: a case report. J Med Case Rep. 2015;9:190.

10. Callens S, De Roo A, Colebunders R. Fanconi-like syndrome and rhabdomyolysis in a person with HIV infection on highly active antiretroviral treatment including tenofovir. J Inf Secur. 2003;47(3):262-3.

11. Marcellin P, Buti M, Krastev Z, de Man RA, Zeuzem S, Lou L, Gaggar A, Flaherty JF, Massetto B, Lin L, Dinh P, Subramanian GM, McHutchison JG, Flisiak R, Gurel S, Dusheiko GM, Heathcote EJ. Kinetics of hepatitis B surface antigen loss in patients with $\mathrm{HBeAg-positive} \mathrm{chronic} \mathrm{hepatitis} \mathrm{B} \mathrm{treated}$ with tenofovir disoproxil fumarate. J Hepatol. 2014;61(6):1228-37.

12. Piratvisuth $T$, Komolmit $P$, Tanwandee $T$, Sukeepaisarnjaroen $W$, Chan $H L$, Pessoa MG, Fassio E, Ono SK, Bessone F, Daruich J, Zeuzem S, Cheinquer H, Pathan R, Dong Y, Trylesinski A. 52-week efficacy and safety of telbivudine with conditional tenofovir intensification at week 24 in HBeAg-positive chronic hepatitis B. PLoS One. 2013:8(2):e54279.

13. Leung NW, Herrmann E, Lau GK, Chan HL, So TM, Zeuzem S, Dong Y, Trylesinski A, Naoumov NV. Early Viral Kinetics with Telbivudine, Tenofovir or Combination of Both in Immunotolerant Patients with Hepatitis B e Antigen-Positive Chronic Hepatitis B. Infect Dis Ther. 2014;3(2):191-202.

14. Johnson AA, Ray AS, Hanes J, Suo Z, Colacino JM, Anderson KS, Johnson KA Toxicity of antiviral nucleoside analogs and the human mitochondrial DNA polymerase. J Biol Chem. 2001;276:40847-57.

15. Kohler JJ, Lewis W. A brief overview of mechanisms of mitochondrial toxicity from NRTIs. Environ Mol Mutagen. 2007:48(3-4):166-72.

16. Mazzucco CE, Hamatake RK, Colonno RJ, Tenney DJ. Entecavir for treatment of hepatitis B virus displays no in vitro mitochondrial toxicity or DNA polymerase gamma inhibition. Antimicrob Agents Chemother. 2008;52:598-605.

\section{Submit your next manuscript to BioMed Central and we will help you at every step:}

- We accept pre-submission inquiries

- Our selector tool helps you to find the most relevant journal

- We provide round the clock customer support

- Convenient online submission

- Thorough peer review

- Inclusion in PubMed and all major indexing services

- Maximum visibility for your research

Submit your manuscript at www.biomedcentral.com/submit
) Biomed Central 